\title{
"Acrescentar Anos a Vida e Vida aos Anos Vividos": Um olhar foucaultiano sobre a gestão da velhice no programa Mais Vida, em Minas Gerais
}

Corrêa Passo, Leandro; Oliveira Barreto, Raquel; de Pádua Carrieri, Alexandre

"Acrescentar Anos a Vida e Vida aos Anos Vividos": Um olhar foucaultiano sobre a gestão da velhice no programa Mais Vida, em Minas Gerais

Administração Pública e Gestão Social, vol. 12, núm. 1, 2020

Universidade Federal de Viçosa, Brasil

Disponible en: http://www.redalyc.org/articulo.oa?id=351561601014

Esta obra está bajo una Licencia Creative Commons Atribución-NoComercial-SinDerivar 3.0 Internacional. 


\section{"Acrescentar Anos a Vida e Vida aos Anos Vividos": Um olhar foucaultiano sobre a gestão da velhice no programa Mais Vida, em Minas Gerais}

"Adding Years to Life and Life to the Living Years": a Foucaultian look at the management of aging under the Mais Vida program in Minas Gerais

"Añadir años a la vida y vida a los años vividos": Una mirada foucaultiana sobre la gestión de la senilidad en el programa Más Vida, en Minas Gerais

Leandro Corrêa Passo

Universidade Federal de Minas Gerais (CEPEAD/

Redalyc: http://www.redalyc.org/articulo.oa?

UFMG), Brasil

adm.leandrocorrea@gmail.com

Raquel Oliveira Barreto

Universidade Federal de Minas Gerais (CEPEAD/

UFMG)Instituto Federal do Norte de Minas Gerais -

Campus Araçuaí, Brasil

prof.raquel.barreto@gmail.com

Alexandre de Pádua Carrieri

Universidade Federal de Minas Gerais, Brasil

aguiar.paduacarrieri@terra.com.br

Recepción: 23 Octubre 2017

Aprobación: 22 Abril 2019

Publicación: 01 Enero 2020

\section{Resumo:}

O envelhecimento é um fenômeno mundial e no Brasil não é diferente: A projeção é de que 1/3 de brasileiros, em 2060, tenham 60 anos ou mais. A partir da perspectiva foucaultiana da governabilidade e da biopolítica, objetivamos analisar como o Programa Mais Vida se propõe a realizar a gestão da velhice em Minas Gerais, inspirados pela arqueologia de Michel Foucault para propiciar um olhar diferente, realizando uma análise da legislação brasileira e, de forma específica, sobre as regulamentações e práticas do Programa. Foi possível perceber o desejo que temos de viver mais como fio condutor que liga o indivíduo à população que será gerida. A família e a sociedade serão chamadas para cuidar dos seus idosos na busca por eficiência. Logo, o idoso será alvo de uma biopolítica, normatizado, subjetivado, disciplinado e examinado, sendo compelido a se autogerir para manter-se ativo e saudável.

Palavras-chave: Governamentalidade, Idoso, Políticas públicas.

\section{Abstract:}

Aging is a worldwide phenomenon and it is no different in Brazil: It is projected that $1 / 3$ of Brazilians, by 2060 , will be 60 years old or older. From the foucaltian perspective of governability and biopolitics, we aim to analyze how the Mais Vida Program proposes to carry out the management of aging in the Brazilian state of Minas Gerais. Based on Michel Foucault's archeology, we provide a different perspective by carrying out an analysis of Brazilian legislation and, specifically, the program regulations and practices. The desire to live longer was identified as the essential feature of the program treatment group. Families and society will be called to care for their elderly due to efficiency reasons and soon the elderly will be the target of a biopolitics: Normalized, subjectivated, disciplined and examined, they will be compelled to self-manage in order to remain active and healthy.

KeYWORDS: Governmentality, Aging, Public policy.

\section{Resumen:}

El envejecimiento es un fenómeno mundial y, en Brasil, no es diferente: Se proyecta que 1/3 de brasileños, en 2060 , tendrá 60 años o más. A partir de la perspectiva foucaltiana de la gobernabilidad y de la biopolítica, objetivamos analizar cómo el Programa Más Vida se propone realizar la gestión del envejecimiento en el estado brasileño de Minas Gerais. Basados en la arqueología de Michel 
Foucault, analizamos la legislación brasileña y, de forma específica, las regulaciones y prácticas del programa. El deseo de vivir más fue identificado como la característica esencial de los individuos que forman el grupo de tratamiento del programa. La familia y la sociedad serán llamadas para cuidar de sus ancianos en la búsqueda de eficiencia y, luego, el anciano será objecto de una biopolítica: Normatizado, subjetivado, disciplinado y examinado, será obligado a autogerirse para mantenerse activo y sano.

Palabras clave: Gobernabilidad, Senilidad, Políticas públicas.

\section{INTRODUÇÃO}

O envelhecimento populacional é uma realidade não apenas no Brasil, mas em todo o mundo. De acordo com o Relatório Mundial de Envelhecimento e Saúde publicado em 2015 pela Organização Mundial de Saúde (OMS), a população acima dos 60 anos atingirá o marco de 2 bilhões de pessoas em todo o mundo até o ano de 2050 (OMS, 2015). Esse envelhecimento da população acompanha o aumento da expectativa de vida dos sujeitos, como no caso específico do Brasil, em que uma criança nascida no país em 2015 tem uma expectativa de vida que supera em 20 anos a idade máxima esperada para uma criança que nasceu há 50 anos. Segundo dados do Instituto Brasileiro de Geografia e Estatística (IBGE) de 2018, em 2060 um quarto da população brasileira deverá ter mais que 65 anos, o que significa cerca de 52,8 milhões de idosos, enquanto em 2018 a proporção era de 9,2\%, ou seja, 19,2 milhões. Os números e estatísticas justificam e colocam como imperativa a necessidade de, entre outras coisas, gerenciar e administrar a velhice.

Diante disso, um dos aspectos que despertam o interesse sobre o tema do envelhecimento e da velhice refere-se a sua transformação em um problema social contemporâneo (Debert, 1994; Tótora, 1994; 2013). Debert (1992, p. 33) alerta para este processo, que ela denomina de “[...] socialização progressiva da gestão da velhice", ou seja, o processo pelo qual a velhice deixa de ser uma questão pertencente apenas à esfera familiar e torna-se objeto do poder público e das organizações privadas. Tótora $(2008 ; 2015)$ coaduna com esta visão discutindo a percepção vigente dos idosos como um grupo de risco, em que se deseja afastar o adoecimento e a morte. Nesse esteio, vários são os questionamentos que emergem acerca dos impactos dessa realidade nos mais diferentes âmbitos: Sistemas de saúde e de seguridade social, mercado de trabalho, assistência social, novas necessidades de consumo, dentre outros (Alcântara, Camarano, \& Giacomin, 2016).

Neste artigo nos interessa o modo como o envelhecimento tem repercutido na criação de políticas públicas e programas, especificamente na área da saúde. Objetivamos, a partir da perspectiva foucaultiana da governabilidade e da biopolítica, analisar como o Programa Mais Vida, uma política de atenção à saúde do idoso implementada pelo governo de Minas Gerais (MG), se propõe a realizar a gestão da velhice. Dito de outro modo, pretendemos mostrar como o idoso é elaborado e praticado sob um enfoque da política de saúde. “Acrescentar anos à vida e vida aos anos vividos", este é o mote do projeto que demonstra em certa medida qual é o seu foco principal, promover a longevidade com qualidade de vida.

Tal discussão parte do pressuposto de que a velhice na sociedade contemporânea é tutelada e está submetida a diferentes estratégias de gestão da vida. Esta constatação baseia-se no entendimento de que a velhice tem sido constituída de forma homogeneizante e naturalizada, o que é realizado por meio da governabilidade e a favor dela. O exemplo clássico dessa homogeneização é a criação da chamada "Terceira Idade" ou "Melhor Idade", uma categoria social definida pela vivência de uma velhice "saudável”, "ativa” e "produtiva". Interessante observar, como explora Tótora (2008), que a conformação da velhice se exerce não apenas sobre aqueles que são velhos, mas abarca a sociedade como um todo por meio de discursos preparatórios do tipo "alimente-se bem para envelhecer de forma saudável”.

Neste contexto de homogeneização e normatização, de que forma o envelhecimento é trabalhado e inserido nas definições e ações desse programa de atenção à saúde do idoso de Minas Gerais? Como fruto de uma proposta inspirada na arqueologia de Foucault, buscamos caminhos para a construção de um corpus para entender a política de atenção à saúde do idoso em Minas Gerais, baseado nos atos normativos emitidos pelas instituições "gestoras" da saúde. Assim, considerando os atos como formações discursivas, isto é, permeados 
por diversos feixes discursivos que poderiam grassar entre distintos saberes que buscam gerir, conhecer, diagnosticar e legislar sobre o tema da velhice, procuramos construir uma analítica que evidencie as técnicas de governamentalidade presentes na política pública de atenção à saúde do idoso em Minas Gerais.

Destaca-se que a escolha pelo enfoque no Programa Mais Vida se deu em função da sua eleição, a partir de 2010, como um dos projetos prioritários do estado de Minas Gerais na área da saúde. Tal priorização se deu com o intuito de operacionalizar, em nível estadual, o que preconizava as diretrizes até então estipuladas em nível federal. Em certa medida, a consolidação do Programa significou o reconhecimento, por parte do estado mineiro, da necessidade de pensar práticas específicas e organizadas para o atendimento do público idoso em evidente crescimento. Nesse sentido, compreender de que forma esse programa se estruturou revela-se um propósito importante aos estudiosos do campo da Gestão Pública, em especial para aqueles interessados em lançar um olhar crítico e reflexivo sobre as políticas públicas no campo do envelhecimento e seus desdobramentos.

Para a construção deste trabalho que, conforme expomos, se inspira na arqueologia de Foucault, realizamos uma investigação de caráter documental, iniciando pela busca e análise da legislação brasileira sobre o assunto. De forma específica, posteriormente nos debruçamos sobre o programa Mais Vida, suas regulamentações e práticas. Ressaltamos que a intenção foi utilizar alguns fundamentos ou elementos operatórios de Foucault como um ferramental analítico de uma maneira particular e flexível, mas não por isso menos rigorosa, tendo em vista propiciar um olhar diferente sobre a política pública em foco.

\section{NotAS SOBRE A CONSTRUÇÃO BIOPOLÍTICA DA VELHICE NA CONTEMPORANEIDADE}

O "ser velho" na sociedade contemporânea é um espaço de embates e forças diversas, o que nos faz refutar veementemente visões homogeneizantes sobre o tema. Partimos aqui da compreensão de que esse sujeito velho/idoso é uma construção social que emerge e se reconstrói em meio aos embates discursivos e, portanto, de poder. Uma parte dos discursos difundidos remete aos estereótipos negativos da velhice, os quais retratam um momento da vida inevitavelmente marcado por certa decadência das faculdades físicas, psíquicas e sociais. Outra parte dos discursos e práticas preconizadas buscam construir imagens positivas como formas de inclusão desse grupo social por meio de expressóes e modos de ser, como a "terceira idade" ou a "melhor idade". (Debert, 1999; Tótora, 2013).

Entende-se, da mesma forma, que o próprio processo de periodização da vida constitui uma construção social. Como expõe Debert (1994), dentro de uma mesma sociedade é possível identificar comportamentos diferentes de sujeitos inseridos arbitrariamente na mesma faixa etária. Tal delimitação de fronteiras etárias é parte de um processo amplo que envolve a institucionalização da vida cronológica, ou seja, uma organização social que se dá a partir da classificação etária do sujeito. Conforme Debert (1994, p. 18), essa institucionalização "está presente na organização do sistema produtivo, nas instituições educativas, no mercado de consumo e nas políticas públicas, que cada vez mais têm como alvo grupos etários específicos”. Nesse sentido, retomamos a ideia de que sobre a velhice tem recaído o status de problema social e, como tal, deve ser tratado, resolvido e remediado. Números são amplamente utilizados para justificar a relevância de estudar esse fenômeno, mas não se pode restringir a questão ao universo do quantitativo e, mais uma vez, a algo que nesse momento deve ser consertado (Tótora, 2013).

Para entender esta proposta de gestão da velhice e da construção de verdades acerca do envelhecimento no estado de Minas, recorremos às noções de biopolítica e governamentalidade de Foucault $(2003,2008 a)$. Como explica Prado Filho (2006), a governamentalidade seria, nos termos foucaultianos, a aplicação de técnicas de governo que possibilitam o exercício do poder sobre uma população. Foucault (2008b) explicita que a necessidade de uma gestão da vida social foi uma demanda resultante da formação do Estado Moderno, fazendo emergir nesse contexto vários objetos passíveis de ações de governo. O enfoque nesse momento passa a ser então o exercício do biopoder ${ }^{[1]}$, ou seja, “[...] o conjunto dos mecanismos pelos quais aquilo que, na 
espécie humana, constitui suas características biológicas fundamentais vai poder entrar numa política, numa estratégia política, numa estratégia geral de poder" (Foucault, 2008a, p. 3). Prado Filho (2006) ratifica esse cenário explicando que se trata do momento em que os fenômenos inerentes à vida humana são transportados para uma estrutura de saber e de poder.

Martins e Peixoto Junior (2009), por sua vez, destacam que a preocupação do Estado com a vida acontece principalmente por meio do saber médico. Esses autores argumentam que a articulação entre a medicalização da sociedade e o governo da vida realizada por Foucault foi uma das condições de possibilidade para o aparecimento do biopoder. Nesse sentido, de acordo com Martins e Peixoto Junior (2009), Foucault confere a medicalização da sociedade a processos que estão relacionados à amplificação do saber médico e que caracterizam a medicina na segunda metade do século XVIII.

Matos e Vieira (2014) estudaram a maneira pela qual o biopoder, por meio do discurso médico-científico, teve efeitos sobre a elaboração da velhice na atualidade. Os autores demonstram que a partir do século XVII, com o desenvolvimento da medicina, o idoso passa a ser estudado e examinado e que, por conseguinte, o biopoder passou a influenciar a representação do idoso na sociedade.

É importante notar que no século XVII o biopoder era caracterizado em torno da problemática das disciplinas, tendo como objeto os corpos dos indivíduos. Nessa época, a medicina dedicava-se ao cuidado do doente e das doenças (Martins \& Peixoto Junior, 2009). Nesse sentido, havia uma tecnologia política, baseada nesse campo de saber-poder, que podia ser denominada de "anátomo-política”. Já em um segundo momento, na metade do século XVIII, o biopoder desloca-se do corpo dos indivíduos para o conjunto dos indivíduos. Passa a ter a espécie humana como alvo e a população como objeto. Para Schramm (2014, p. 13):

A biopolítica, ou - como preferem alguns - as biopolíticas, podem ser vistas, de acordo com a filologia do termo, como a reconfiguração da relação entre política e vida, referente ao fato de esta ter se tornado objeto direto do exercício do poder, chamado, por isso, de "biopoder", e por concentrar-se sobre os corpos e sua produtividade, isto é, sobre a atividade governamental representada por lógicas econômicas e de gestão, ou seja, pelo encontro entre saberes e práticas de gestão da população produtiva, individuando na lógica e na práxis econômica a verdadeira governabilidade biopolítica moderna, utilitarista e orientada ao sucesso.

Estas práticas de regular e governar a vida humana ensejam, por sua vez, um conjunto de saberes que serão tomados como ciência. O que Foucault quer então ressaltar é um movimento que trouxe a população como finalidade das técnicas de governo, que possibilitou e garantiu a formação de instituições e de um corpo de funcionários encarregados da gestão da população. O que se observa dessas práticas de governamentalidade acerca da velhice? Podemos dizer que emerge um novo enunciado acerca da velhice, com inclusões e exclusões de significado (Foucault, 2004).

Matos e Vieira (2014) exaltam que a criação da geriatria e da gerontologia no início do séc. XX validaram esse "novo" discurso sobre a velhice, o qual permanece e se consolida na contemporaneidade. O enunciado que a partir de então qualifica a velhice como a melhor idade muda a concepção de um idoso ocioso para, agora, um idoso dinâmico, que se cuida e que está integrado à sociedade. Ao mesmo tempo em que o idoso deve se ver dessa forma, a biopolítica deverá proporcionar os meios para essa subjetivação e atuação. Estas técnicas têm como foco o corpo do indivíduo, a disciplina e a normalização de costumes, como ensina Foucault, abarcando o individual pelo coletivo.

\section{FeIXes Discursivos E ENUNCIADOS SOBRE A VELHICE NA LEGISLAÇÃo BRASILEIRA}

Inspirados pela proposta analítica genealógica de Foucault, iniciamos o processo de compreensão desta construção biopolítica da velhice a partir de um levantamento da legislação e marcos regulatórios associados ao idoso e a sua saúde no país. Esclarecemos que esse não foi um esforço exaustivo no sentido de esgotar esses elementos, mas sim de escavar com vistas a apreender os feixes discursivos, por meio dos quais pudéssemos 
extrair enunciados para entender a conformação geral do nosso objeto. Para tal, fizemos consultas formais ${ }^{\text {[2] }}$ à Secretaria Estadual de Saúde de Minas Gerais (SES-MG) e ao Ministério da Saúde (MS), de modo a fazer o mapeamento não só a nível estadual, mas também nacional.

Devido à necessidade incontornável de estabelecer um recorte, convencionamos como referências para delinear o feixe discursivo em questão a Constituição da República Federativa do Brasil de 1988, a Política Nacional do Idoso de 1994, o Estatuto do Idoso de 2003 e a Política Nacional de Saúde da Pessoa Idosa de 2006 e, como desdobramento, o Programa Mais Vida, foco deste artigo.

Figura 1 - Linha do tempo dos principais marcos regulatórios sobre a saúde do idoso

\begin{tabular}{|c|c|c|c|c|c|c|c|}
\hline $\begin{array}{l}\text { Política } \\
\text { Nacional do } \\
\text { Idoso (PNI) }\end{array}$ & $\begin{array}{l}\text { Regulamentação } \\
\text { da PNI }\end{array}$ & $\begin{array}{l}\text { Estatuto do } \\
\text { Idoso }\end{array}$ & $\begin{array}{l}\text { Política } \\
\text { Nacional da } \\
\text { Pessoa Idosa }\end{array}$ & $\begin{array}{l}\text { Programa } \\
\text { Mais Vida }\end{array}$ & $\begin{array}{l}\text { Alterações } \\
\text { no Programa } \\
\text { Mais Vida }\end{array}$ & $\begin{array}{l}\text { Compromisso } \\
\text { Nacional para } \\
o \\
\text { envelhecimento } \\
\text { ativo. }\end{array}$ & $\begin{array}{l}\text { Convenção } \\
\text { Interamericana } \\
\text { sobre } \\
\text { proteção dos } \\
\text { Direitos } \\
\text { Humanos das } \\
\text { Pessoas } \\
\text { Idosas }\end{array}$ \\
\hline $04 / 01 / 1994$ & $03 / 07 / 1999$ & $01 / 10 / 2003$ & $19 / 10 / 2006$ & $19 / 09 / 2008$ & $07 / 12 / 2010$ & $30 / 09 / 2013$ & $15 / 06 / 2015$ \\
\hline
\end{tabular}

Fonte: Elaboração própria, 2017.

A partir da análise desses marcos regulatórios, três enunciados foram identificados: $\mathrm{O}$ de dignidade e bem-estar, o da família e o da intersetorialidade. Vamos, rapidamente, falar sobre cada um deles para então compreendermos o Programa Mais Vida.

O primeiro enunciado identificado foi o da dignidade e do bem-estar. Tal enunciado está explícito na Carta Magna, em que ambos são colocados como fundamentos do nosso Estado democrático de direito. No artigo terceiro desse mesmo documento os objetivos da República são afirmados, incluindo a promoção do bemestar de todos, sem quaisquer preconceitos, incluindo o etário. Mais adiante, no artigo sexto da Constituição, onde constam os direitos fundamentais, a saúde aparece como algo a ser assegurado a todos. No Estatuto do Idoso, em seu $2^{\circ}$ parágrafo, define-se que

Art. 2o O idoso goza de todos os direitos fundamentais inerentes à pessoa humana, sem prejuízo da proteção integral de que trata esta Lei, assegurando-se-lhe, por lei ou por outros meios, todas as oportunidades e facilidades, para preservação de sua saúde física e mental e seu aperfeiçoamento moral, intelectual, espiritual e social, em condições de liberdade e dignidade (BRASIL, 2003, p.1).

Saraiva (2016), em estudo acerca da tutela constitucional à pessoa idosa, demonstrou que a dignidade da pessoa humana é a principal maneira de proteção atribuída ao idoso pela Constituição de 1988. Embora a autora afirme que a "dignidade da pessoa humana" é um conceito de árdua e complexa delimitação, considerase incontestável que ela inclua os direitos sociais arrolados no artigo $6^{\circ} \mathrm{da}$ Carta, dentre eles a saúde.

Retomando a perspectiva foucaultiana, podemos observar uma relação entre a biopolítica e os direitos humanos. Sobre esse assunto, Both (2008) argumenta que o discurso dos direitos humanos é justamente aquele que sustenta a ação biopolítica do Estado, dando-lhe legitimidade. O autor afirma que "será efetivando direitos através de políticas públicas que o Estado cuidará da vida" (Both, 2008, p.102). Com efeito, vemos no artigo $6^{\circ}$ da norma de Proteção dos Direitos Humanos das Pessoas Idosas que "os Estados parte adotarão todas as medidas necessárias para garantir ao idoso o gozo efetivo do direito à vida e o direito a viver com dignidade na velhice até o fim de seus dias, em igualdade de condições com outros setores da população”.

O segundo enunciado identificado refere-se ao da família. A leitura de todos os marcos legais e regulatórios demonstra que o cuidado do idoso é atribuído a uma coletividade: Família, sociedade e Estado. Interessante destacar que a família sempre é colocada como a primeira instância, revelando o seu papel central nesse contexto. Como um dispositivo de segurança, nos termos de Foucault, o art. 229 da Carta Magna cita que 
são os filhos maiores que devem ajudar e amparar os pais na velhice. O Estatuto do Idoso reforça a construção desta rede de cuidados na qual a família é agente prioritário em seu art. $3^{\circ}$. Tal centralidade da família encontra eco no feixe discursivo da gerontologia, em que a família é considerada o "habitat natural da pessoa humana" (Leme \& Silva, 1996. p. 92). Segundo os autores, a família é importante em todos os estágios do ciclo de vida do ser humano, mas é essencialmente relevante durante o início do ciclo, a infância, e ao seu final, na senilidade.

Nesse sentido, a decisão do legislador em determinar a família como o núcleo para o cuidado ao idoso parece residir na expectativa de que o ambiente familiar seja o local privilegiado para o envelhecimento saudável. Zimerman (2000), entretanto, chama a atenção para o fato de que essa é apenas uma das possibilidades de vivência, uma vez que em sua experiência como gerontóloga identificou diferentes dinâmicas familiares. Dito de outro modo, a autora argumenta que não necessariamente a família propicia ao idoso o tal envelhecimento saudável, não só pela ocorrência de maus tratos, mas até mesmo pela proteção excessiva que gera dependência.

Retomando as contribuições foucaultianas, é interessante resgatar a participação da família no processo da governamentalização do Estado. $\mathrm{O}$ autor sublinha que a questão de como bem governar o Estado emerge no século XVI e que, numa linha ascendente, para a realização desse bom governo, é preciso bem governar a si mesmo e, em continuidade, bem governar a família. Quando se refere ao bom governo da família, o autor remete ao pai de família e ao cuidado dos filhos. É preciso bem cuidar dos filhos para que estes sejam boas pessoas, sejam "dóceis e produtivos" (Foucault, 1997).

Entretanto, na atualidade, emerge o problema do cuidado dos filhos para com os pais, uma vez que o número de integrantes das famílias vem diminuindo. Temos idosos sem filhos e sem netos. Entretanto, a resposta estatal permanece a mesma: A família é colocada no centro do cuidado com os idosos e, nesse sentido, trata-se de uma relação solidária. Conforme art. 229 da Constituição: "Os pais têm o dever de assistir, criar e educar os filhos menores, e os filhos maiores têm o dever de ajudar e amparar os pais na velhice, carência ou enfermidade".

O terceiro enunciado consiste no da intersetorialidade. É interessante ressaltar que, após as definições gerais e mais amplas colocadas na Constituição, são as leis que irão dar contornos mais definidos e perceptíveis. No caso do cuidado com o idoso, destaca-se o lançamento da Política Nacional do Idoso (PNI) como a primeira tentativa de especificar as ações com o intuito de assegurar o que está previsto na Carta Magna. Cielo e Vaz (2009) revelam que das reivindicações e dos debates entre idosos ativos e aposentados, profissionais de gerontologia e geriatria e membros da sociedade civil, surgiu finalmente um texto base que fundamentou a lei.

O alcance da finalidade da lei, de acordo com as diretrizes estabelecidas, está ancorado nas formas de implantação da política. Assim, no Capítulo IV as ações governamentais para a implementação da PNI mobilizam uma série de atores que circulam por grandes áreas: I - de promoção e assistência social, II - saúde, III - educação, IV - trabalho e previdência social, V - habitação e urbanismo, VI - justiça e VIII - cultura, esporte e lazer. Nesse sentido, ficou claro que a operacionalização dessa política envolveria a intersetorialidade da gestão pública: Uma "articulação de saberes e experiências que propiciam planejamento, realização e avaliação de políticas, programas e projetos, ou seja, condições para alcançar resultados sinérgicos em situações complexas" (Fernandes, Castro, \& Maron, 2013, p. 5).

Cavalcante, Carvalho e Medeiros (2012) explicam que a PNI é uma política entremeada principalmente por ações que abarcam a seguridade social no Brasil, a saber: Saúde, previdência e assistência social. Nesse sentido, eles afirmam que há consenso entre os formuladores sobre a necessidade de articulação intersetorial, entretanto, existem obstáculos para a efetivação da sua execução tanto pela inexistência de estrutura de todo o conjunto das áreas que envolvem a PNI quanto pela pressão de grupos contrários aos princípios da PNI.É importante ressaltar que a intersetorialidade, em específico das ações de saúde da pessoa idosa foi reforçada 
na Política Nacional de Saúde da Pessoa Idosa (PNPSI). Essa política especifica a saúde do idoso, declarando a necessidade expressa da intersetorialidade:

A prática da intersetorialidade pressupõe o reconhecimento de parceiros e de órgãos governamentais e não-governamentais que trabalham com a população idosa. A organização do cuidado intersetorial a essa população evita duplicidade de ações, corrige distorções e potencializa a rede de solidariedade (Brasil, 2006, s.p.).

Nessa mesma perspectiva, a Convenção Interamericana sobre Proteção dos Direitos Humanos das Pessoas Idosas também aponta para a necessidade de políticas intersetoriais no que tange a saúde do idoso, de modo que seja alcançado um atendimento denominado integral.

Os enunciados "do bem-estar e dignidade" e "da família e da intersetorialidade" nos permitem compreender, de forma geral, em que discursos a legislação brasileira sobre o idoso se fundamenta. São enunciados recorrentes que se complementam ao longo de toda a rede normativa que trata dessa população. Nos termos de Foucault, são estas normas que balizam e que possibilitam o exercício da governabilidade. Como estes discursos reverberam no programa Mais Vida, foco deste trabalho? É o que discutiremos a seguir.

\section{Programa Mais Vida: Por uma analítica da rede de atenção ao idoso mineiro}

O Programa Mais Vida foi criado em setembro de 2008, com a publicação da Resolução da Secretaria do Estado de Saúde (SES-MG) no 1.583 e atualizado pela resolução SES nº 2.603 de 7 de dezembro de 2010, com o objetivo de estruturar a rede de atenção à saúde da população idosa em Minas Gerais - Rede Mais Vida. Em 2008, o programa pertencia à carteira de projetos associados do Estado de Minas Gerais na área da saúde, mas foi em 2010 que ocorreu a sua incorporação ao rol de projetos prioritários. Consiste em uma iniciativa que vai ao encontro do que é proposto na Política Nacional de Saúde da Pessoa Idosa (PNSI), na medida em que objetiva trabalhar na promoção de medidas capazes de fomentar a autonomia e a independência da pessoa idosa (Brasil, 2006).

Podemos dizer que a construção da política específica de Minas Gerais se deu a partir das diretrizes nacionais: A Política Nacional do Idoso - PNI -, a PNSI, o Estatuto do Idoso e a Constituição Federal. “Acrescentar anos à vida e vida aos anos vividos" (Bandeira, 2014, s.p). Tal emblema, que dá título a este trabalho, expressa a proposta do programa: Trata-se de uma iniciativa dentro do âmbito das políticas públicas da saúde cujo objeto é a gestão da velhice, dito de outra forma, a promoção de uma "nova" proposta de velhice pautada na construção de uma longevidade saudável e autônoma. Esta proposta é evidenciada na missão do programa: "Buscar a manutenção da capacidade funcional e autonomia do indivíduo através da promoção de hábitos saudáveis de vida e o diagnóstico precoce, visando diminuir as incapacidades e contribuir para melhoria da qualidade de vida dessa população [...]" (Bandeira, 2014, s.p).

Para trilhar este caminho de gestão de uma velhice de temporalidade ampliada e saudável, o programa estabelece alguns objetivos:

I. Estruturar a rede de atenção à saúde da população idosa em Minas Gerais por meio de sistema articulado, regionalizado e integrado de ações qualificadas em saúde;

II. Manter, melhorar e/ou reabilitar a funcionalidade e autonomia, de acordo com as necessidades de cada idoso;

III. Assegurar os princípios doutrinários do SUS de equidade, universalidade e integralidade;

IV. Promover o aumento dos anos vividos da pessoa idosa, com vistas à manutenção de sua capacidade funcional e autonomia por meio da atenção global à saúde;

V. Qualificar os profissionais da rede pública de atenção à saúde para ofertar atenção integral e qualificada ao idoso;

VI. Captar e acolher a população acima de 60 (sessenta) anos de idade e identificar suas necessidades 
VII. Proporcionar a promoção e a prevenção da saúde da população idosa. (MINAS GERAIS, 2010, p.2).

Tais objetivos podem ser sintetizados em uma proposta de trabalho que se insere nos princípios do Sistema Único de Saúde (SUS), o que inclui uma atuação intersetorial e cooperativa entre os atores da rede e atores externos, focando na gestão da velhice sob uma perspectiva da manutenção da saúde. Dentro da perspectiva da governamentalidade e do biopoder, algumas observações se fazem necessárias. Qual a proposta, ou melhor, em que bases de fato repousa o programa Mais Vida?

Torna-se evidente que o idoso será trabalhado e terá sua vida organizada, parametrizada. Não basta envelhecer, deve-se envelhecer do jeito certo, afinal, "[...] o direito de morte que outrora era concebido ao arbítrio e à necessidade do soberano, agora vai apoiar-se nas exigências de um corpo social a fim de garantir vida, mantê-la e desenvolvê-la" (Matos \& Vieira, 2014, p. 202). Como discutimos anteriormente, o que se deseja para este corpo social? Saúde para que, em última instância, se tenha produtividade. Se tal produtividade não representa, para alguns idosos, a permanência no mercado para a geração de riquezas, significa, por outro lado, a redução dos custos excessivos que o atendimento a essa população representa ao sistema de saúde, bem como sua desejada incorporação ao mercado consumidor.

É interessante ressaltar que propor às pessoas que vivam mais e melhor vai ao encontro de um desejo particular dos sujeitos, mas o intuito é que tal proposta passe a ser alvo de uma técnica de governo a nível populacional. (Foucault, 2008b). O filósofo argumenta que tal naturalidade do desejo caracteriza a população e a partir disso ela se torna acessível à técnica governamental. O desejo é a busca de interesse pelo indivíduo, mas que acabará por produzir um interesse coletivo. Segundo Foucault (2008a) o indivíduo pode até se enganar com o seu interesse, mas estas mutações acabarão produzindo algo que é de interesse da população e algo que será alvo das técnicas de governo.

Foucault (2008a) traça características da governamentalidade mostrando a relação do governo com o acontecimento. Nesse sentido, quais acontecimentos relacionam-se ao programa Mais Vida? O que se pretende evitar? Podemos inferir que o governo quer evitar a sobrecarga do sistema de saúde com idosos debilitados, quer evitar elevação dos custos, uma vez que esses sujeitos ocupam muitos leitos e por mais tempo. Ademais, quer refrear o aumento dos gastos com remédios, procedimentos e cirurgias, dentre outros. Wong e Carvalho (2006) discutem os impactos desse aumento de custos associados à saúde, destacando projeções como a de que em 2025 o número de pessoas com 60 anos ou mais com alguma doença crônica será de aproximadamente 27 milhões, podendo alcançar a marca de 50 milhões em 2050. Tendo em vista as doenças crônicas serem justamente aquelas que demandam atenção permanente à saúde, pode-se dimensionar o aumento das necessidades em termos de equipamentos, medicamentos e profissionais. Estes dados são corroborados pela Organização Mundial da Saúde (OMS), que destaca a hipertensão, a diabetes mellitus e as doenças cardiovasculares como as enfermidades mais comuns que acometem essa população (OMS, 2015). Nas palavras de Wong e Carvalho (2006, p. 21), "dadas as limitações do sistema de saúde pública brasileiro, o rápido processo de envelhecimento aponta para a necessidade de se redefinirem as políticas deste setor, com o intuito de prevenir, ou pelo menos atenuar, o desamparo das gerações mais velhas". Contra esses acontecimentos, políticas públicas foram delineadas. Foi estabelecido um sistema jurídico legal: A Constituição Federal, a Política Nacional do Idoso, a Política Nacional de Saúde da Pessoa Idosa e o Estatuto do Idoso. Foram desenvolvidos regulamentos e resoluções da Secretaria Estadual de Saúde de Minas Gerais que estipularam e normatizam o Mais Vida.

Para alcançar o objetivo de viver mais e melhor, estratégias para implantação e implementação do Mais Vida foram traçadas. Assim, vimos que no inciso I do artigo é objetivo do Mais Vida estruturar a rede de atenção à saúde da população idosa em Minas Gerais por meio de sistema articulado, regionalizado e integrado de ações qualificadas em saúde. Nesse ponto, a nossa análise recai sobre este enunciado: A estruturação de uma rede de atenção. O que é essa técnica de rede de atenção? Por que essa estratégia? Quem a enuncia? De acordo com o documento, a atenção primária e as redes de atenção à saúde, o desenvolvimento e 
a implantação das Redes de Atenção à Saúde (RAS) no Sistema Único de Saúde (SUS) foram protagonizados pelo Conselho Nacional de Secretários de Saúde.

O Conselho Nacional de Secretários de Saúde (CONASS) é uma entidade de direito privado e sem fins lucrativos que se pauta pelos princípios que regem o direito público e que congrega os secretários e seus substitutos legais enquanto gestores oficiais das Secretarias de Estado da Saúde (SES) dos estados e do Distrito Federal. Dentre as finalidades do Conselho destacamos as funções de promover a capacitação e a pesquisa científica para o aprimoramento do SUS e produzir e difundir conhecimento como possíveis motivadores para a atuação do CONASS na implantação das RAS. Tal implantação se deu em 4 etapas distintas: A concepção teórico-conceitual, a difusão da proposta, a institucionalização das RAS e o momento atual de implantação das RAS (CONASS, 2015a).

A primeira etapa foi iniciada em 2004 com a elaboração da proposta de RAS. Essa proposta foi baseada em modelos internacionais e adaptada para a realidade do Sistema Único de Saúde. A segunda etapa visou desenvolver e aprimorar os fundamentos teóricos e operacionais das RAS e obter ambiência aderente ao novo modelo. Para isso, a proposta foi amplamente divulgada e comunicada. Nesse sentido, foram realizadas as Oficinas de RAS em várias Secretarias Estaduais de Saúde e em coordenações do Ministério da Saúde. De acordo com o CONASS (2015a, p.9): "Por sua extensão e abrangência, pode-se afirmar que a ação do CONASS criou, em atores sociais relevantes do SUS, entendimento e adesão à ideia de RAS que formulara".

A terceira etapa, por sua vez, consistiu na afirmação da RAS como forma de organização dos serviços de saúde no SUS. Para isso, o CONASS efetuou discussões no Ministério da Saúde e com o Conselho Nacional de Secretarias Municipais de Saúde para a elaboração de um modelo consensual ${ }^{[1]}$. Por fim, a quarta etapa descrita pelo CONASS (2015a) é o momento atual de implantação das RAS. Nesse sentido, o objetivo é implantar a RAS prioritária nas regiões metropolitanas com o apoio do CONASS. Para analisarmos este conceito de Rede de Atenção à Saúde, vamos relembrar que a governamentalidade modernamente associase à condução, cuidado e sustento dos indivíduos no conjunto da população. De acordo com Santos (2010), esta gestão foi se tornando cada vez mais complexa à medida que outras demandas foram sendo pedidas e incorporadas pela sociedade. Assim, diferentes modelos de governamentalidade política emergiram.

Do século XVI até o século XVIII desenvolveu-se o modelo da Razão de Estado, proposta pela classe dos políticos que se configurava à época. A Razão de Estado tem como princípio fundamental a racionalidade do governo assentada na manutenção do próprio Estado. Nesse sentido, essa razão valeu-se de dois conjuntos tecnológicos: A tecnologia diplomático-militar e a polícia. De acordo com Santos (2010), na Razão de Estado aparece o objetivo de assegurar produtividade, segurança e felicidade. No conceito de RAS vemos a preocupação de estabelecer uma política pública que organize os serviços de saúde de forma produtiva. A atenção à saúde da população deve ser prestada no tempo certo, no lugar certo, com o custo certo, com a qualidade certa, conforme é expresso.

Já o segundo modelo de governamentalidade política é o liberalismo. Ele se desenvolveu na segunda metade do século XVIII e se intensificou no século XX, dando forma ao chamado neoliberalismo. O liberalismo tinha como princípio a limitação das atividades governamentais, tendo como norte a economia e o mercado. Como ressalta Foucault, ele não é uma substituição da razão de Estado, ele é uma reconfiguração da razão de Estado dando uma nova racionalidade à gestão governamental. É entendido como uma forma de realizar as atividades do governo cujo objetivo, conforme Santos (2010, p.198), “[...] é determinar o que se deve governar e como se deve governar. [...] Guiado pela regra de maximização da economia, o liberalismo almeja a construção de um governo econômico".

Nas redes de atenção à saúde, o cuidado deve ser realizado com responsabilidade sanitária e econômica e deve gerar valor para a população. A responsabilidade sanitária é a definida nas competências de cada gestor doSUS em seu âmbito de atuação, União, estado ou município. Já a responsabilidade econômica significa que haverá um cálculo baseado em um saber que direcionará o governo na busca de eficiência. Mendes (2011), por exemplo, sustenta que para um sistema de saúde eficiente é imprescindível alcance de escala. Ele ilustra, 
apoiando-se em outros estudos (Aletras et al., $1997^{[2]}$; Andrade et al., $2007^{\text {[3] }}$ ), que economias de escalas são encontradas em hospitais que possuem de 100 a 450 leitos. Esse exemplo revela a busca pela geração de valor para a população de modo a minimizar custos.

Santos (2010) argumenta que a principal característica do liberalismo foi assegurar o complexo jogo entre os interesses particulares e garantir a liberdade suficiente para que esse jogo possa acontecer. Nesse sentido, valeu-se da utilização de dispositivos de segurança muito mais do que de dispositivos disciplinares. Contudo, estes não foram abandonados e sim reconfigurados, processo do qual o panóptico é exemplo. É dada liberdade para o funcionamento dos comportamentos individuais e de produção, contudo, eles são ainda vigiados para que se possa intervir caso o desempenho não seja adequado.

No conceito de RAS a atenção à saúde será coordenada pela atenção primária à saúde. Nesse nível de atenção, a população é constantemente observada pelos médicos e pela equipe de saúde da família. Essa equipe não cessará na busca de informações sobre a saúde das famílias, visando gerar informações de saúde de cada um, do território e da população. Isso é a política pública na forma de uma biopolítica na qual a vida com seus mecanismos entra no domínio da racionalização e faz do saber-poder um agente da transformação humana.

Nesse sentido, de manutenção de um controle sobre a população idosa, faz-se necessário questionar: De que idoso estamos falando? $\mathrm{Na}$ resolução do Mais Vida, no $\$ 2^{\circ}$ do artigo primeiro é definido

$\$ 2^{\circ}$ Para fins desta Resolução considera-se:

I. Idoso: $\mathrm{O}$ indivíduo acima de 60 (sessenta) anos de idade;

II. Idoso frágil: Conforme Linha Guia “Atenção à Saúde do Idoso/SES-MG”, é aquele com 80 (oitenta) anos de idade ou mais ou aquele com 60 (sessenta) anos ou mais que apresente no mínimo uma das características abaixo:

a) Polipatologias (5 - cinco - diagnósticos ou mais);

b) Polifarmácia ( 5 - cinco - medicamentos ou mais ao dia);

c) Imobilidade parcial ou total;

d) Incontinência urinária ou fecal;

e) Instabilidade postural (quedas de repetição);

f) Incapacidade cognitiva (declínio cognitivo, síndrome demencial, depressão, delirium);

g) Dependência nas atividades básicas de vida diária (ABVD's). (Minas Gerais, 2010, p.2).

A definição de idoso permanece a mesma dada pela OMS, a novidade apresentada pela política é a conceituação de idoso frágil. É interessante notar tal definição como o exercício da disciplina. Em um primeiro momento consiste em catalogar e analisar os indivíduos, segmentando-os conforme o potencial de cada um. Posteriormente, a disciplina determina as sequências ideais para cada grupo para, por fim, estipular os procedimentos de treinamento, adestramento e de controle constantes. Neste momento são demarcados os aptos e os incapazes, ou no caso da política, aqueles que serão alvo ou não de determinada assistência.

Se retomarmos os enunciados identificados anteriormente quando analisada a legislação brasileira acerca da saúde do idoso (bem-estar e dignidade, família e intersetorialidade), podemos encontrá-los traduzidos no Programa Mais Vida. A busca pelo bem-estar tangencia toda a construção do programa, que pauta suas ações principalmente na manutenção da independência do idoso, o que também se insere no complexo conceito de dignidade humana (Saraiva, 2016). A família também se faz presente como agente que contribui para o alcance dos objetivos do programa, principalmente no que tange ao acompanhamento dos idosos. A intersetorialidade da mesma forma é colocada como situação sine qua non para a execução da política, o que se torna explícito, por exemplo, com o conceito de Rede de Atenção à Saúde.

A partir dessas definições legais o programa Mais Vida foi então colocado em prática. Como principais ações foram adotadas a descentralização das ações voltadas à saúde da pessoa idosa por meio de um sistema de rede com fluxos estabelecidos, combinados com a criação do centro de referência secundária denominado 
Mais Vida, a estipulação de prêmios para Instituições de Longa Permanecia para Idosos (ILPI), as ações de capacitação de profissionais de saúde no que tange aos idosos, a distribuição de cadernetas de saúde específica da pessoa idosa e a preocupação com a cobertura vacinal contra influenza.

\section{A PRÁtICA DA POLÍTICA OU A POLÍTICA EM PRÁTICA}

O Centro Mais Vida (CMV) é um ponto de atenção secundária da Rede Mais Vida que tem como objetivo oferecer atenção especializada à saúde da população idosa considerada frágil ou de risco, referenciada pela unidade de Atenção Primária a Saúde (Bandeira, 2014). De acordo com Bandeira (2014), o CMV tem como produto a elaboração de um Plano de Cuidados a ser implantado pela equipe da Atenção Primária à Saúde (APS), com o suporte técnico dos profissionais do Centro, atuando na educação continuada dos profissionais e na geração de conhecimento.

O CMV é o local privilegiado onde o conhecimento sobre o idoso será extraído e repassado. Dito de outro modo, é o local onde o idoso será analisado, esquadrinhado, examinado, avaliado. Nesse mesmo espaço o sujeito da política receberá informações e orientações, o que faz com que o CMV se configure não apenas como um local em que o conhecimento será aplicado, mas ao mesmo tempo (re)configurado e legitimado. De acordo com Foucault, o exame é uma técnica que com suas perguntas e respostas e com os sistemas de notas e classificações envolve um campo de saber e de poder. De fato, o idoso irá preencher cadernetas com o objetivo de que seja identificada a sua situação de saúde e vulnerabilidade, sendo a partir disso elaborado um plano de cuidados para que ele possa ser tratado.

Nesse sentido, um exame escrito permite ao geriatra conhecer o idoso e ao mesmo tempo transmitir suas orientações. Assim, o exame faz certa interligação entre o exercício do poder e uma modalidade de formação de saber. Foucault (1997, p. 156) expõe que o "exame inverte a economia da visibilidade no exercício do poder”. Segundo ele, o poder disciplinar não aparece, é invisível, ao contrário de outras formas de poder. Pogrebinschi (2004, p. 191) diz que: "[...] o poder disciplinar deve manter-se na invisibilidade para funcionar, pois que a sua invisibilidade ressalta a visibilidade daqueles que a ele se sujeitam, de modo que a sua eficácia é constante e permanente". Logo, são os idosos que têm que ser olhados e observados para que sejam sujeitos e objetos da política pública.

Outro ponto apresentado por Foucault (1997, p. 157) é que "o exame faz também a individualidade entrar num campo documentário". O idoso será observado e suas informações irão compor um documento. O exame é ritualístico e tem como suporte a caderneta de saúde da pessoa idosa. Nesse documento são inventariados, entre outros elementos, os hábitos de vida do idoso, cirurgias anteriormente realizadas e alergias a medicamentos. Por meio da caderneta são estabelecidos controles de vacinação, glicemia, pressão arterial, entre outros. Com efeito, Foucault (1997, p. 157) afirma que "os procedimentos de exame são acompanhados imediatamente de um sistema de registro intenso e de acumulação documentária. Um poder de escrita é constituído como uma peça essencial nas engrenagens da disciplina”.

Esses registros documentais irão permitir a constituição do idoso como objeto descritível e analisável. Foucault expõe que o exame por meio das técnicas de escrita ou de documentação transforma cada indivíduo em um caso. Segundo o autor, "o caso é o indivíduo tal como pode ser descrito [...], comparado a outros e isso em sua própria individualidade, e é também o indivíduo que tem que ser classificado, normalizado, excluído" (Foucault, 1997, p. 159). Por outro lado, os registros escritos também irão possibilitar a descrição de grupos, a distribuição em uma população.

No que diz respeito à população abarcada pelos serviços do CMVs, identificou-se que em Minas Gerais existem três unidades localizadas nas cidades de Belo Horizonte, Montes Claros e Juiz de Fora, como pode ser observado no mapa abaixo. 


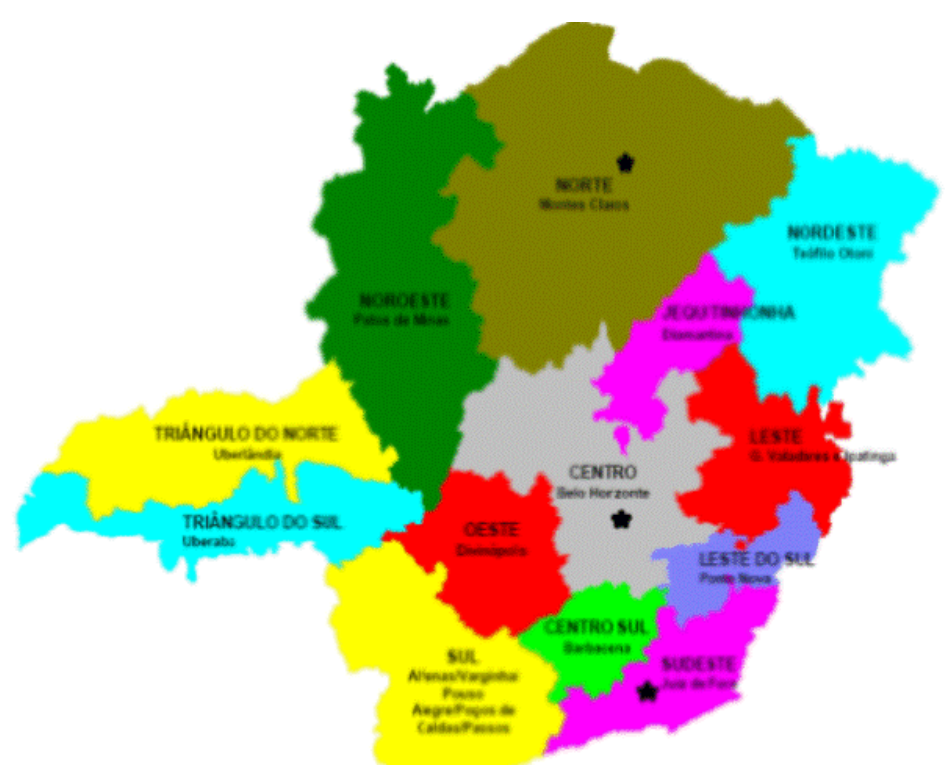

Figura 2 - Centros Mais Vida nas Macrorregiões de Saúde Minas Gerais Fonte: Bandeira, 2014.

O mapa demonstra, como dito anteriormente, a localização dos três CMVs implantados em Minas Gerais. Embora não seja o escopo da discussão aqui empreendida, a localização dos CMVs em relação à amplitude territorial do estado chama a atenção e traz à tona a questão das barreiras geográficas existentes para que este atendimento especializado aos idosos seja realizado de forma mais ampliada. Segundo Bandeira (2014), a ideia era que o número de centros fosse crescendo ao longo do tempo, chegando às outras macrorregiões. Em relação a essas unidades implantadas, o autor esclarece que apenas o CMV do Norte de Minas não é capaz de abranger a totalidade da população idosa a ele subscrita, chegando ao índice de $77,53 \%$ de cobertura. Do ponto de vista até o momento conduzido, pode-se problematizar que a localização desses primeiros centros foi estratégica, visando dar os primeiros passos nesse projeto de exercício da governamentalidade e da gestão dessa população em especial (Santos, 2010).

Além dos CMVs, com a cartilha do idoso e com as ações de capacitação de profissionais de saúde, podemos ver a governamentalização do Estado ancorada em especial no poder disciplinar. Conforme nos ensina Foucault, o poder disciplinar está sustentado no saber científico e no saber médico, em especial. É a criação de uma anátomo-política do corpo do idoso que legitima, regulamenta e disciplinariza. Nesse sentido, não somente os idosos serão disciplinarizados, pois haverá a criação de uma massa de profissionais capazes de enunciar o discurso, replicá-lo. De acordo com dados da SES-MG, em 2012 foram capacitados para o atendimento aos idosos 2.073 profissionais de saúde, via Canal Minas Saúde.

A cartilha do idoso é, conforme se qualifica "um guia para viver mais e melhor" e está disponível no sítio eletrônico da Secretaria de Estado de Saúde de Minas Gerais. Nessa cartilha são colocadas algumas instruções para que o idoso pratique exercícios físicos, para que exercite a mente, para que se alimente de forma adequada e para que possa prevenir quedas. Há também recomendações para dormir, para adquirir e tomar medicamentos, dicas de higiene, vacinas e ainda sobre sexualidade. Como diz Foucault (2008, p. 60): "Uma boa disciplina é o que lhes diz a cada instante o que vocês devem fazer". A figura 5 ilustra estas colocações. 


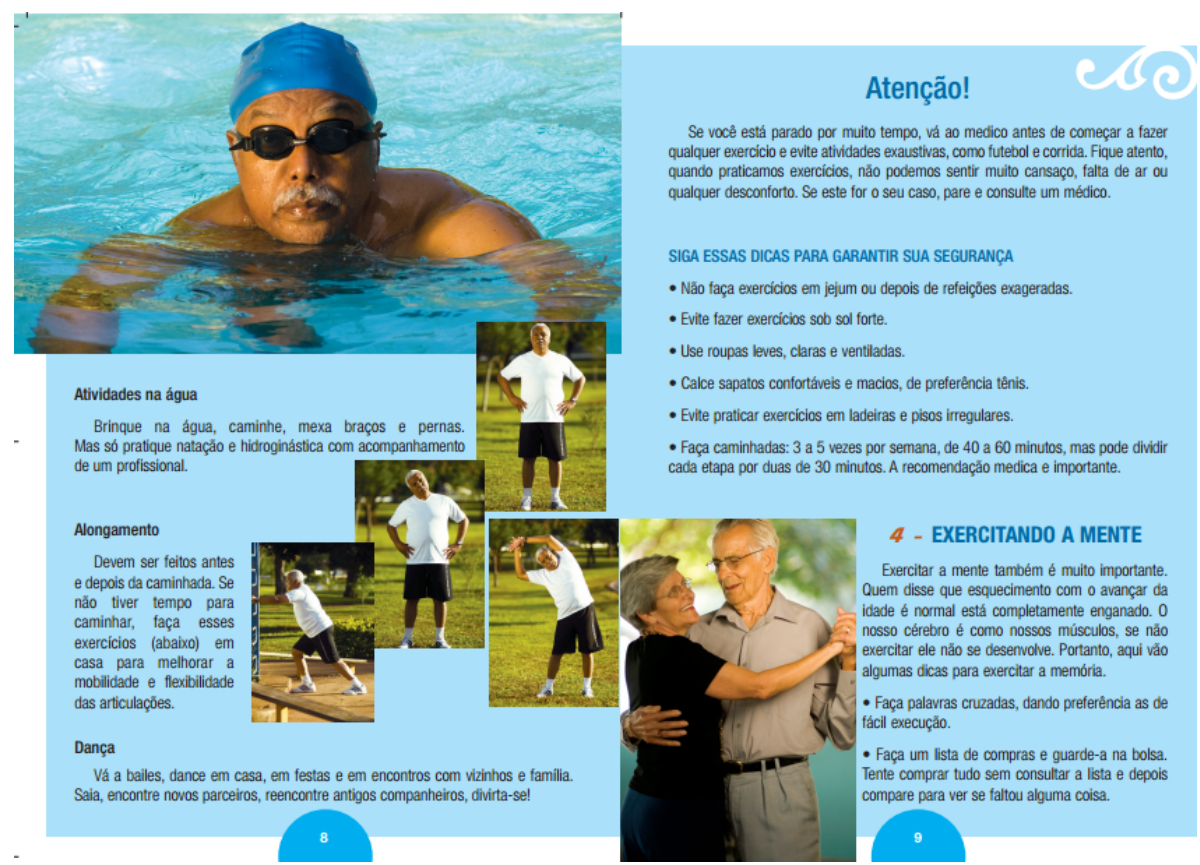

Figura 3 - Partes do Guia para viver mais e melhor

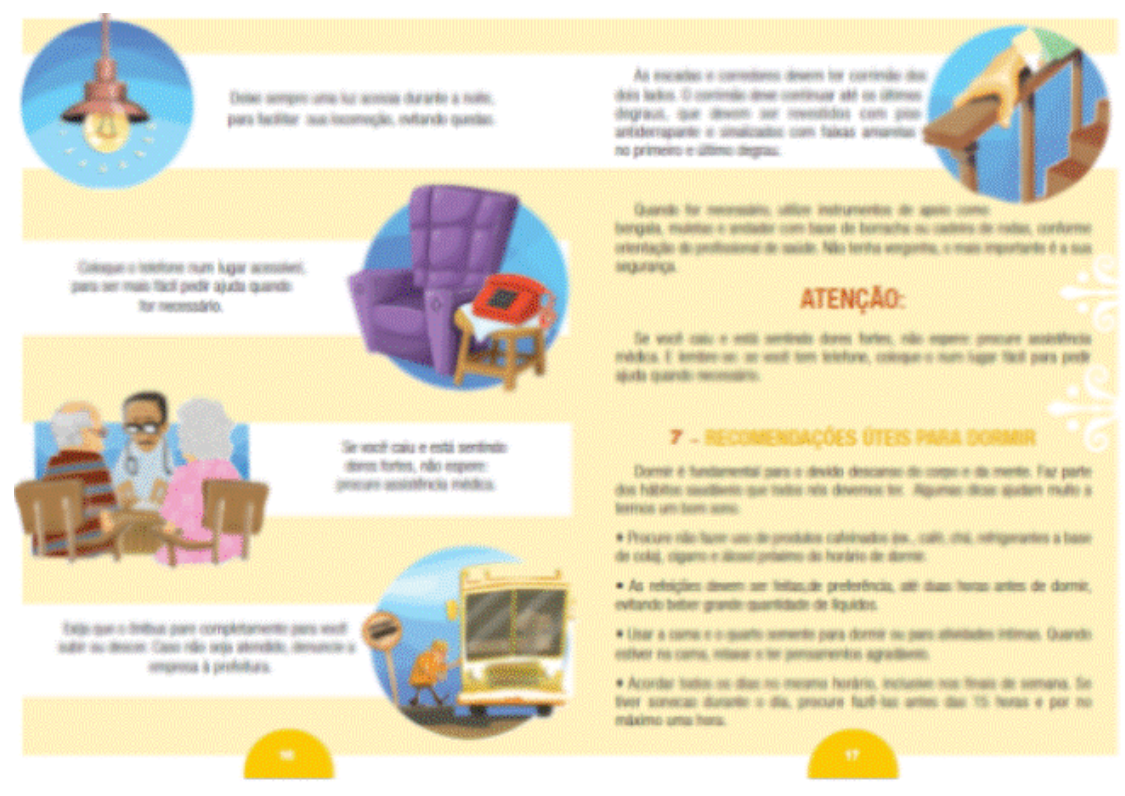

Fonte: Guia para viver mais e melhor.

Nesse sentido, o Guia para se viver mais e melhor é um dispositivo que age ou procura agir tanto junto ao sujeito idoso quanto junto à população de idosos. Assim, é pedido ao idoso que se comporte como um indivíduo que cuide de sua saúde, que atue como um "novo velho", conforme vimos na categorização acima. Por outro lado, podemos dizer que as recomendações do guia são para mudar condutas, mudar comportamentos e agir enquanto membros de uma população e não de um povo. Foucault (2008, p. 57) afirma que, com esse deslocamento dos dispositivos para a população, “[...] temos aí, [...], comportamentos que fazem com que cada um dos indivíduos funcione como membro, [...] como elemento dessa coisa que se quer administrar da melhor maneira possível, a saber, a população”. Em contraposição ele coloca que: 
[...] o povo é aquele que se comporta em relação a essa gestão da população, [...] como se não fizesse parte desse sujeito-objeto coletivo que é a população, como se se pusesse fora dela, e, por conseguinte, é ele que, como povo que se recusa a ser população vai desajustar o sistema. (FOUCAULT, 2008, p. 57)

Nesse contexto, o idoso deveria conduzir sua vida conforme as recomendações do guia, porquanto é membro de uma população. Ele não deve agir como povo, pois isso implicaria em desajuste do sistema. Vemos então a ação biopolítica e a governamentalidade atuarem por meio de uma tecnologia, o Guia Viver Mais e Melhor.

\section{CONSIDERAÇÕES SOBRE A ANALÍTICA}

O percurso de compreender os feixes discursivos presentes na legislação brasileira acerca da saúde do idoso e então aprofundar na proposta do Programa Mais Vida revelou aspectos importantes sobre a temática da velhice. Percebemos que a preocupação manifesta na legislação aponta para a promoção de uma velhice massificada amplamente preocupada com a saúde e com a qualidade de vida. Os impactos dessa atitude seriam, grosso modo, a redução do adoecimento e, consequentemente, a queda nos custos na área da saúde e um aumento do potencial produtivo desses sujeitos, algo extremamente valorizado em nossa sociedade. Obviamente, entende-se que as necessidades não se restringem à área da saúde, mas é sobre ela que está o maior enfoque. Nesse ponto, as verdades produzidas pelo campo das ciências médicas ecoam e se legitimam.

A análise do Programa Mais Vida demonstrou claramente o caráter de tutela sobre o idoso: Ele é classificado, examinado, medicado e remediado. A vigilância busca a conformação e o controle sobre os corpos e, de uma forma mais ampla, sobre a população. As reflexões que emergem dessa análise são justamente as seguintes: Que modelo ideal é este que a política visa alcançar? Ele é real e factível para a maior parte da população brasileira? Essas questões se fazem necessárias se encararmos o claro risco a que estamos submetidos sob o olhar dessa política: $\mathrm{O}$ processo de responsabilização individual pelo envelhecimento. Dito de outro modo, a grande disseminação de um discurso prescritivo cria a expectativa de que basta o seguimento das diretrizes para que se alcance o modelo ideal de velhice. Nesse sentido, a gestão da velhice passa por um processo de autogestão por parte dos sujeitos.

Tendo em vista a diversidade que compõe a população brasileira, podemos de alguma forma imaginar a diversidade que marca a população idosa de uma forma geral. Ainda que recortes sejam feitos para a definição de uma política pública, como a definição do Idoso Frágil, muitas vivências ainda coexistem neste espaço. Propor um modelo único e ideal de envelhecimento nos parece um processo que busca construir uma igualdade a partir de uma realidade bastante desigual. Cotidianamente esses recortes acabam por gerar exclusão e falta de assistência a uma parte da população, talvez aquela que mais dependa das políticas públicas. Esse argumento pode ser esclarecido a partir de questões como os altos custos que podem envolver uma alimentação saudável, a dificuldade de acesso a atividades físicas, os laços familiares fragilizados que muitas vezes significam abandono dos idosos, as unidades de saúde em números reduzidos e muitas vezes distantes para o idoso, as diferenças entre a vivência da velhice sob a perspectiva de gênero (velhos são diferentes de velhas), dentre outros. No caso deste trabalho, por exemplo, no Programa Mais Vida são apenas três Centros Mais Vida com o intuito de atender a um estado com proporções territoriais significativas como Minas Gerais.

É importante destacar que, conforme vimos, a família e a sociedade estão sendo chamadas para cuidar dos seus idosos. Os filhos deverão cuidar dos seus pais, mesmo que $1 / 4$ dos casais não tenham filhos, conforme dados do IBGE (2013). O governo buscará a eficiência, mas não se pode considerar a família como certeza de que o idoso terá bons cuidados, além do fato de imputar a ela uma gama desproporcional de deveres. Por outro lado, isso também poderá levar à obstrução de que outras soluções sejam pensadas e construídas por meio de investimentos governamentais, sendo que a própria Política Nacional de Saúde da Pessoa Idosa aponta que a legislação brasileira relativa aos cuidados da população idosa, apesar de ser bastante avançada, tem uma 
prática que ainda é insatisfatória. As discussões que aqui empreendemos de forma alguma esgotam os vários desafios que se colocam quando falamos de políticas públicas para idosos.

Ao final deste artigo esperamos ter contribuído para a ampliação do debate acerca das políticas públicas direcionadas aos idosos trazendo, em especial, uma abordagem ancorada nas ideias de Foucault. Nesse sentido, reconhecemos que tal analítica não se pretende exaustiva, tampouco conclusiva, mas que seja compreendida como um outro olhar possível e necessário mediante uma realidade que não podemos negar: A população mundial está envelhecendo. Especialmente sobre o Programa Mais Vida, sugere-se a realização de novas pesquisas que avaliem a sua operacionalização, envolvendo não apenas fontes documentais, sendo essa uma das limitações desse estudo, mas incluindo as perspectivas de seus formuladores da política e, principalmente, dos seus usuários.

\section{REFERÊNCIAS}

Alcântara, A. de O.; Camarano, A. A.; Giacomin, K. C. (Orgs.) (2016). Política Nacional do Idoso: velhas e novas questôes. Rio de Janeiro: IPEA.

Bandeira, E. M. F. de S. (2014). Rede Mais Vida: Rede de Atenção à Saúde do Idoso. Secretaria de Estado de Saúde, Diretoria de Redes Assistenciais, Coordenação de Atenção à Saúde do Idoso.

Brasil (2003). Decreto no 4.740, de 13 de Junho de 2003. Aprova o Estatuto e o Quadro Demonstrativo dos Cargos em Comissão e Funções Gratificadas da Fundação Instituto Brasileiro de Geografia e Estatística IBGE, e dá outras providências. Disponível em http://www.ibge.gov.br/home/disseminacao/eventos/missao/ estatuto.shtm. Acesso em: 08 out. 2016.

Brasil (2006). Ministério da Saúde. Secretaria de Atenção à Saúde. Departamento de Ações Programáticas e Estratégicas. Área Técnica de Saúde do Idoso. Um guia para se viver mais e melhor. 2006. Disponível em: http:// www.saude.mg.gov.br/images/documentos/Cartilha\%20Idoso\%20Final.pdf. Acesso em: 20 abr. 2017.

Both, V. (2008). O biopoder e o discurso dos direitos humanos: um estudo a partir de Michel Foucault. Dissertação (Mestrado em Filosofia). Universidade do Vale do Rio dos Sinos. São Leopoldo Recuperado em: http://www.educadores.diaadia.pr.gov.br/arquivos/File/2010/artigos_teses/FILOSOFIA/Dissertacoes/ Valdevir_Both.pdf Acesso em: 10 de junho de 2017.

Cavalcanti, P.; Carvalho, R. N.; Medeiros, K. T. (2012). Intersetorialidade, Políticas Sociais e Velhice no Brasil: entre a falácia e a efetivação do direito social. Universidade do Estado do Rio de Janeiro. Laboratório de Estudos Contemporâneos. Polêmica, v. 11, n. 4, outubro/dezembro.

Conselho Nacional de Secretários de Saúde - CONASS (2015). A atenção primária e as redes de atenção à saúde. Brasília: CONASS (Coleção Progestores - Para entender a gestão do SUS-2015). Disponível em: http:// www.conass.org.br/biblioteca/a-atencao-primaria-e-as-redes-de-atencao-a-saude/. Acesso em: 20 fev.2017.

Debert, G. G. (1992). Família, Classe Social e Etnicidade: Um Balanço da Bibliografia sobre a Experiência de Envelhecimento. Revista BIB, Rio de Janeiro, n. 33,1. ${ }^{\circ}$ Semestre, pp. 33-49.

Debert, G. G. (1994). Antropologia e Envelhecimento. 2a.ed. CAMPINAS: IFCH/UNICAMP, v. 700. 118p.

Debert, G. G. (1999). A reinvenção da velhice: socialização e processos de reprivatização do envelhecimento. São Paulo: EDUSP.

Fernandes, A.; Castro, C.; Maron, J. (2013). Desafios para a implementação de políticas públicas: intersetorialidade e regionalização. Anais do VI Congresso CONSAD de Gestão Pública, Brasília (DF). Disponível em: http:// www.escoladegestao.pr.gov.br/arquivos/File/2013/V_CONSAD/VI_CONSAD/025.pdf. Acesso em 18 mar. 2017.

Foucault, M. (1997). Vigiar e Punir. 20ed. Petrópolis: Vozes.

Foucault, M. (2008). Nascimento da Biopolítica. Curso no Collège de France (1978-1979). São Paulo: Martins Fontes.

Foucault, M. (2008). Segurança, território, população: curso dado no Collège de France (1977-1978). Tradução de Eduardo Brandão. São Paulo: Martins Fontes, 2008. 
Foucault, M. (2003). A “governamentabilidade” In: FOUCAULT, M. Ética, Sexualidade e Política. Rio de Janeiro: Forense Universitária, p. 281-305 (Coleção Ditos e Escritos IV).

Foucault, M. (2004). A ética do cuidado de si como prática de liberdade. In: FOUCAULT, M. Ética, Sexualidade e Política. Rio de Janeiro: Forense Universitária, p. 264-287 (Coleção Ditos e Escritos V).

Foucault, M. (2013). Microfísica do Poder. 10 ed. Organização e tradução de Roberto Machado. Rio de Janeiro: Graal.

IBGE (2016). Projeções e estimativas da população do Brasil e das Unidades da Federação. Disponível em: http:// www.ibge.gov.br/apps/populacao/projecao. Acessado em 30/10/2016.

IBGE (2013). Síntese de Indicadores Sociais: Uma análise das condições de vida da população Brasileira. Rio de Janeiro, 2013. Disponível em http://biblioteca.ibge.gov.br/visualizacao/livros/liv66777.pdf. Acesso em 15 nov. 2015.

Leme, L. E. G.; Silva, P. S. C. P. da. (1996). O idoso e a família. In: Papaléo Neto, M. (Org). (1996). Gerontologia. São Paulo: Atheneu, p.92-7.

Martins, L. A. M.; Peixoto Junior, C. A. (2009). Genealogia do biopoder. Psicologia \& Sociedade, v. 21, n.2, p.157-165.

Minas Gerais (2010). Secretaria de Estado de Saúde de Minas Gerais. Resolução SES n 2.603, de 7 de dezembro de 2010. Dispõe sobre o Programa Mais Vida - Rede de Atenção à Saúde do Idoso de Minas Gerais, e dá outras providências. Disponível em: < http://www.saude.mg.gov.br/images/documentos/resolucao_\%202603.pdf>. Acesso em 01 maio. 2016.

Matos, R. K. de S.; V, L. L. F. (2014). Fazer Viver e Deixar Morrer: a Velhice na Era do Biopoder. Psicologia: Ciência e Profissão, v. 34, n.1, p. 196-213.

Mendes, E. V. (2011). As redes de atenção à saúde. 2a ed. Brasília: Organização Pan-Americana da Saúde.

Oliveira, A. D. et. al. (2014). A intersetorialidade nas políticas públicas para o envelhecimento no Brasil. Revista Kairós Gerontologia, São Paulo, v. 17, n.2, p.91-103.

OMS (2015). Relatório Mundial de Envelhecimento e Saúde 2015. Disponível em: http://apps.who.int/iris/ bitstream/10665/186468/6/WHO_FWC_ALC_15.01_por.pdf. Acessado em: 21/10/16.

Organização dos Estados Americanos (OEA) (2015). Convenção Interamericana sobre a Proteção dos Direitos Humanos dos Idosos. Washington, D.C, Disponível em http://portalarquivos.saude.gov.br/images/pdf/2015/ julho/06/CONV.\%20INTER\%20DOS\%20IDOSOS\%20-OEA.pdf. Acesso em 02 abr. 2017.

Prado Filho, K. (2006). Uma história da governamentalidade. Rio de Janeiro: Achiamé.

Santos, R. E. dos (2010). Genealogia da Governamentalidade em Michel Foucault. 2010. 242f. Dissertação (Mestrado em Filosofia) - Belo Horizonte. Faculdade de Filosofia e Ciências Humanas, Universidade Federal de Minas Gerais, Belo Horizonte.

Saraiva, L. L. (2016). A tutela constitucional da pessoa idosa. Conteúdo Jurídico, Brasília - DF. Disponível em: http:// www.conteudojuridico.com.br/?artigos\&ver=2.55852\&seo=1>. Acesso em: 30 jan. 2017.

Schramm, F. R. (2014). Dialética entre liberalismo, paternalismo de Estado e biopolítica. Análise conceitual, implicações bioéticas e democráticas. Revista bioética, Rio de Janeiro, v. 22, n.1, p.10-7, 2014.

Tótora, S. (2006). Ética da vida e o envelhecimento. (2006). In: Côrte, b.; Mercadante, e. f.; Arcuri, I. G. (Org). (2006). Envelhecimento e velhice: um guia para a vida. São Paulo: Vetor. p.26-47.

Tótora, S. (2008). Apontamentos para uma ética do envelhecimento. Revista Kairós, São Paulo, v. 11, n.1, p. 21-38.

Tótora, S. (2008b). A vida nas dobras... as dobras da velhice. Revista A Terceira Idade, v.19, nº43, p.27-38.

Tótora, S. (2013). Genealogia da velhice. In: XXVII Simpósio Nacional de História. Anais... Natal.

Tótora, S. (2015). Velhice: uma estética da existência. São Paulo: EDUC, FAPESP. Zimerman, G. I. (2000). Velhice: aspectos biopsicossociais. Porto Alegre: Artmed.

Wong, L. L. R.; Carvalho, J. A. (2006). The rapid process of aging in Brazil: serious challenges for public policies. Rev Bras Est Pop. 23(1);5-26. 


\section{Notas}

[1] Para saber mais sobre o conceito de biopoder ver FURTADO, R. N.; CAMILO, J. A. O. O conceito de biopoder no pensamento de Michel Foucault. Revista Subjetividades, v. 16, p. 1-11, 2016.

[2] As consultas foram realizadas no período entre os meses de março e abril de 2017 por meio do Portal da Transparência, valendo-se da lei de Acesso a Informação n 12.527, de 18 de novembro de 2011.

[3] Andrade, M. V. et al. (2007). Análise da eficiência hospitalar no estado de Minas Gerais. Belo Horizonte, CEDEPLAR/ UFMG.

\section{BY-NC-ND}

